\title{
Therapeutic Efficacy of Subthreshold Laser Photocoagulation using a Conventional Pattern Scan Laser for Macular Edema in a Retrospective Study
}

\author{
Tomoyasu Shiraya*, Satoshi Kato and Fumiyuki Araki \\ Department of Ophthalmology, Graduate School of Medicine, University of Tokyo, Tokyo, Japan

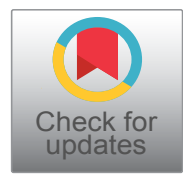

*Corresponding author: Tomoyasu Shiraya, Department of Ophthalmology, Graduate School of Medicine, University of Tokyo, 7-3-1 Hongo, Bunkyo-ku, Tokyo, 113-8655, Japan, Tel: +81 3-3815-5411, Fax: +81 3-3817-0798, E-mail: shiraya01@ gmail.com

\begin{abstract}
Purpose: Subthreshold laser photocoagulation has emerged and is changing minimally invasive treatment for macular edema (ME) affected by retinal vascular diseases. However, this laser method requires specific photocoagulator, and it cannot be introduced at each facility. We investigated the efficacy of subthreshold laser photocoagulation using a conventional pattern scan laser (PS-STLT) in treating ME in clinical practice.
\end{abstract}

Methods: We assessed the effects of PS-STLT treatment in 24 eyes of 24 patients with ME. Seventeen patients had diabetic retinopathy, five had branch retinal vein occlusion, and two had central retinal vein occlusion. All patients underwent PS-STLT treatment between December 2015 and May 2017. The average postoperative observation period was $5.5 \pm 3.4$ months. We evaluated the following parameters before the PS-STLT procedure and at one, two, and three months postoperative: best-corrected visual acuity using logMAR scores, center macular thickness (CMT), and total macular volume (TMV) as determined by optical coherence tomography (OCT). We fixed the $577-\mathrm{nm}$ laser beam of a scanning laser photocoagulator at an area $100 \mu \mathrm{m}$ in diameter, $20 \mathrm{~ms}$, and selected a $2 \times 2$ grid scan pattern using an Area Centralis ${ }^{\circledR}$ lens. The initial laser power of the PS-STLT was $100 \mathrm{~mW}$, and the laser was focused on a specific area of the ME identified by OCT. If spot lesions were visible on ophthalmoscopic examination, the laser power was decreased by $10 \mathrm{~mW}$ to avoid scarring.

Results: The laser power was $76.7 \pm 18.1(50-100) \mathrm{mW}$ and the total laser shots were $374.4 \pm 243.9$. The preoperative logMAR scores and TMV were $0.26 \pm 0.32$ and $9.7 \pm$ $1.6 \mathrm{~mm}^{3}$, respectively. They were $0.28 \pm 0.29$ and $9.6 \pm 3.1$ $\mathrm{mm}^{3}$, at one month postoperative, $0.25 \pm 0.32$ and $9.6 \pm 2.6$ $\mathrm{mm}^{3}$, at two months, and $0.25 \pm 0.31$ and $9.3 \pm 1.7 \mathrm{~mm}^{3}$ at three months. A significant reduction in TMV was observed at three months postoperative $(P<0.01)$, and the CMT had decreased by $\geq 20 \%$ in 10 of 24 eyes $(41.7 \%)$ three months after PS-STLT treatment.

Conclusion: These findings suggest that PS-STLT using a general pattern scan laser for the treatment of ME is effective.

\section{Keywords}

Subthreshold laser photocoagulation, Macular edema, Laser photocoagulation, Optical coherence tomography, Pattern scan laser

\section{Introduction}

Macular edema (ME) is caused by retinal vascular diseases such as diabetic retinopathy (DR), central retinal vein occlusion (CRVO), and branch retinal vein occlusion (BRVO) and is one of the most important causes of visual loss. Specifically, diabetic macular edema (DME) affects approximately $29 \%$ of diabetic patients with a disease duration of 20 years or more [1]; therefore, the frequency and severity of disease should be considered.

The Early Treatment of Diabetic Retinopathy Study (ETDRS) reported the effectiveness of macular laser photocoagulation for the treatment of diffuse DME and concluded that it reduced visual loss by approximately $50 \%$ after 3 years of follow-up [2]. However, subsequent reports showed complications such as scotoma and central vision loss [3], subretinal fibrosis [4], and a subretinal neovascular membrane [5] due to the expansion

Citation: Shiraya T, Kato S, Araki F (2018) Therapeutic Efficacy of Subthreshold Laser Photocoagulation using a Conventional Pattern Scan Laser for Macular Edema in a Retrospective Study. Int J Ophthalmol Clin Res 5:090. doi.org/10.23937/2378-346X/1410090

Accepted: August 09, 2018: Published: August 11, 2018

Copyright: (C) 2018 Shiraya T, et al. This is an open-access article distributed under the terms of the Creative Commons Attribution License, which permits unrestricted use, distribution, and reproduction in any medium, provided the original author and source are credited. 
and fusion of coagulation spots during secular changes.

Later, the Diabetic Retinopathy Clinical Research Network (DRCR.net) re-examined this coagulation technique and reported it as a modified (m) ETDRS focal/grid photocoagulation protocol [6], but the risk of macular tissue damage remained. Therefore, a new treatment was sought.

In recent years, a new concept in photocoagulation methods called subthreshold laser photocoagulation has emerged and is changing non-invasive treatment for diffuse DME. This method includes micropulse laser therapy, a system that continuously transmits extremely short-duration laser irradiation using a micropulse designed to target the retinal pigment epithelium (RPE); it has the characteristic of causing little effect to the outer retina or choroid and no apparent visible colour changes in treated areas $[7,8]$.

The therapeutic effect of subthreshold micropulse laser photocoagulation for DME was first reported in 1997 [9], after which several clinical studies were performed to support the effectiveness of this method [10-13]. Recent research reported that it had the same or better efficacy than the conventional photocoagulation method [14]. In addition, PASCAL ${ }^{\circledR}$ (Topcon, Tokyo, Japan), a photocoagulator capable of using a pattern scanning laser with a high-power, short-duration method has been widely used, and Endpoint Management (EM), which is software equipped with PASCAL ${ }^{\circledR}$, was launched recently and can perform subthreshold laser photocoagulation. However, this is a computational model based on a specific algorithm for the adjustment of laser power with a short coagulation duration of 0.015 seconds without using a micropulse that can perform suitable treatment less invasively. Subthreshold laser photocoagulators are believed to be definitely useful for treating diffuse ME, such as DME, because of the minimally invasive and effective treatment method. However, disseminating this micropulse laser or EM will require a period of time; furthermore, it cannot be introduced at each facility. Previously, we performed EM and conventional pattern scan laser on the rabbit retina to compare the extent of tissue damage at each coagulation spot based on optical coherence tomography (OCT) and histopathological finding, and the results indicated the potential of obtaining effects similar to EM even in conventional models [15].

The present study was carried out to investigate the effect of subthreshold laser photocoagulation for ME associated with retinal vascular disease using a conventional pattern scan laser (subthreshold laser therapy using a pattern scan laser photocoagulator: PS-STLT) in clinical practice.

\section{Methods}

\section{Study design}

Retrospective, non-randomised, interventional case series.

\section{Study population}

Twenty-four patients (24 eyes) observed for 3 months or more after PS-STLT were enrolled in this study, and the average postoperative observation duration was $5.5 \pm 3.4$ months; 17 patients were had DR, five patients had BRVO, and two patients had CRVO. There were 15 men ( 15 eyes) and 9 women ( 9 eyes). The patients ranged from 45 to 81 in age, with a mean age of $67.5 \pm 9.6$ years (mean \pm standard deviation [SD]). DR in diabetic patients $(n=17)$ was classified as moderate or severe non-proliferative DR in 14 patients, and proliferative retinopathy in three patients. All patients were treated at Tsutsumi Eye Clinic (Tokyo, Japan) between December 2015 and May 2017 by a single surgeon (K.S.). Informed consent was obtained from all individual participants included in the study, and all procedures conducted in accordance with the declaration of Helsinki (1964). The exclusion criteria were as follows: patients who underwent (1) Previous vitreous surgery; (2) Previous cataract surgery within 6 months; (3) Previous retinal photocoagulation within 6 months; (4) Had an indication of direct photocoagulation for the closure of microaneurysms; (5) Had a previous intravitreal injection of bevacizumab, ranibizumab, or triamcinolone acetonide (including subtenon triamcinolone acetonide within 6 months), and (6) Had vitreoretinal interface disorders according to OCT findings.

\section{Outcome measures}

Before the PS-STLT procedure and in the first, second, and third postoperative months, we evaluated the following: best-corrected visual acuity (BCVA) using logarithm of the minimum angle of resolution (logMAR) values for statistical analysis; central macular thickness (CMT); and total macular volume (TMV) as determined by OCT (3D OCT-2000, Topcon, Tokyo, Japan). For cases in which CMT improvement was not obtained after treatment, we also used the thickness map mode installed in the OCT system with an ETDRS grid to assess the average thickness $(\mu \mathrm{m})$ before and after treatment specifically in the area with the greatest ME in which the laser photocoagulation was mainly performed. The ETDRS grid was used to demarcate nine zones delimited by solid circles 1,3 , and $6 \mathrm{~mm}$ in diameter centred on the fovea; radial lines were projected onto the fundus of the eye to divide the OCT image grid into nine areas.

\section{Treatment procedures and treatment criteria}

All patients underwent a comprehensive ophthalmic examination, which included BCVA, a slit-lamp examination, indirect fundus examination, and intraocular pressure measurements. Moreover, colour fundus photography and OCT were performed before enrolment in the study. The evaluation of DR stage was carried out using the international severity classification from indirect fundus examination findings. BCVA was calculated in $\log M A R$ units for the statistical analysis. 


\section{Photocoagulation technique}

Using a scanning laser photocoagulator (MC-500 Vix$\mathrm{i}^{\mathrm{TM}}$; Nidek, Gamagori, Japan), we fixed the laser beam at a $100-\mu \mathrm{m}$ spot diameter and $577-\mathrm{nm}$ wavelength for $20 \mathrm{~ms}$ and selected a $2 \times 2$ grid with a 0.5 scan pattern spacing using an Area Centralis ${ }^{\circledR}$ contact lens (Volk Optical Inc., Menter, OH, USA). The initial laser power for PS STLT was $100 \mathrm{~mW}$, and the laser was focused on a specific area of the ME as identified by OCT. PS-STLT is applied for lesions located $200 \mu \mathrm{m}$ or more from fovea. If spot lesions were visible ophthalmoscopically, the laser power was lowered by $10 \mathrm{~mW}$ each time down to an invisible laser spot.

\section{Statistical analysis}

One-way repeated measures ANOVA and Bonferroni correction was performed to compare baseline values with values from 1,2 , and 3 months postoperatively regarding the following outcomes: BCVA (logMAR value), TMV, and CMT. Probability values of less than 0.05 were considered significant. All statistical analyses were performed with EZR (Saitama Medical Centre, Jichi Medical University, Saitama, Japan), a graphical user interface for R (The R Foundation for Statistical Computing, Vienna, Austria). More precisely, it is a modified version of $R$ Commander designed to add statistical functions used frequently in biostatistics [16].

\section{Results}

\section{The mean laser power and the mean total number of laser shots}

No patient demonstrated an ophthalmoscopically detectable laser lesion at any observation point postoperatively. No treatment complication was observed. The mean laser power was $76.7 \pm 18.1 \mathrm{~mW}$ and the mean total number of laser shots was $374.4 \pm 243$.9. No additional treatment with PS-STLT, conventional photocoagulation, drug treatment, or other surgical treatment was necessary.

\section{Alterations in macular parameters according to op- tical coherence tomography findings at 1,2 , and 3 months postoperatively}

The baseline CMT value was $382.1 \pm 146.3$ (range, 184-689) $\mu \mathrm{m}$, the values 1,2 , and 3 months after PSSTLT were $385.8 \pm 173.1 \mu \mathrm{m}, 355.0 \pm 193.9 \mu \mathrm{m}$, and $351.8 \pm 166.6 \mu \mathrm{m}$, respectively. At 3 months after the operation, CMT was reduced by $7.9 \%$; however, CMT was not significantly different within the observation period ( $\mathrm{P}$-values at 1, 2, and 3 months after PS-STLT were 1.0, 1.0, and 1.0, respectively, [one-way repeated measures ANOVA]). Figure 1 shows a scatter diagram of changes in CMT between base line and 3 months after the operation. Ten of 24 eyes $(41.7 \%)$ showed a CMT

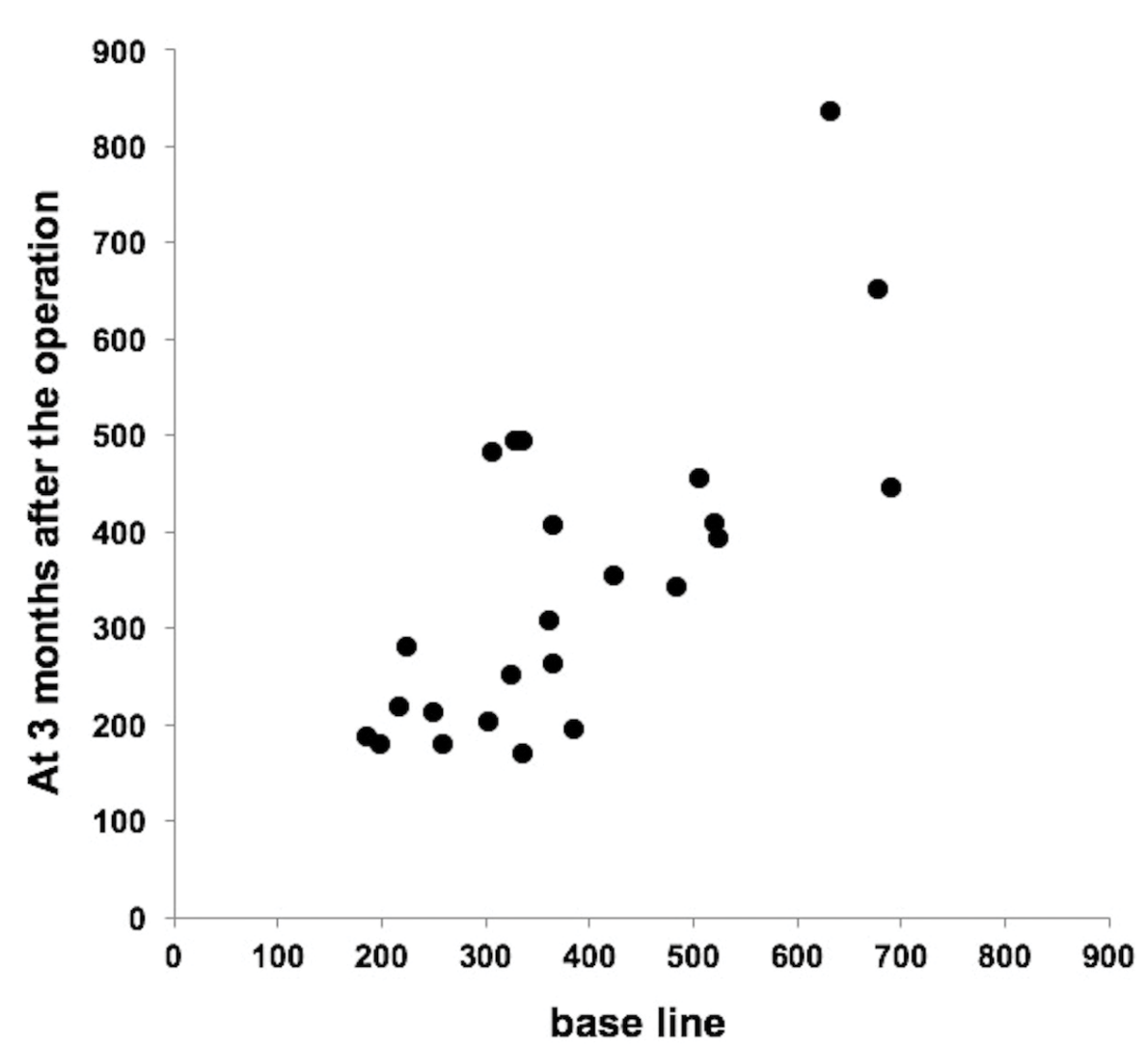

Figure 1: Changes in central macular thickness at 3 months after subthreshold laser therapy using a pattern scan laser photocoagulator $(n=24)$.

Changes in central macular thickness after subthreshold laser therapy using a pattern scan laser photocoagulator between base line and 3 months after the operation. Three severe cases with a CMT exceeding $600 \mu \mathrm{m}$, and six cases with a CMT less than $300 \mu \mathrm{m}$ were included. 

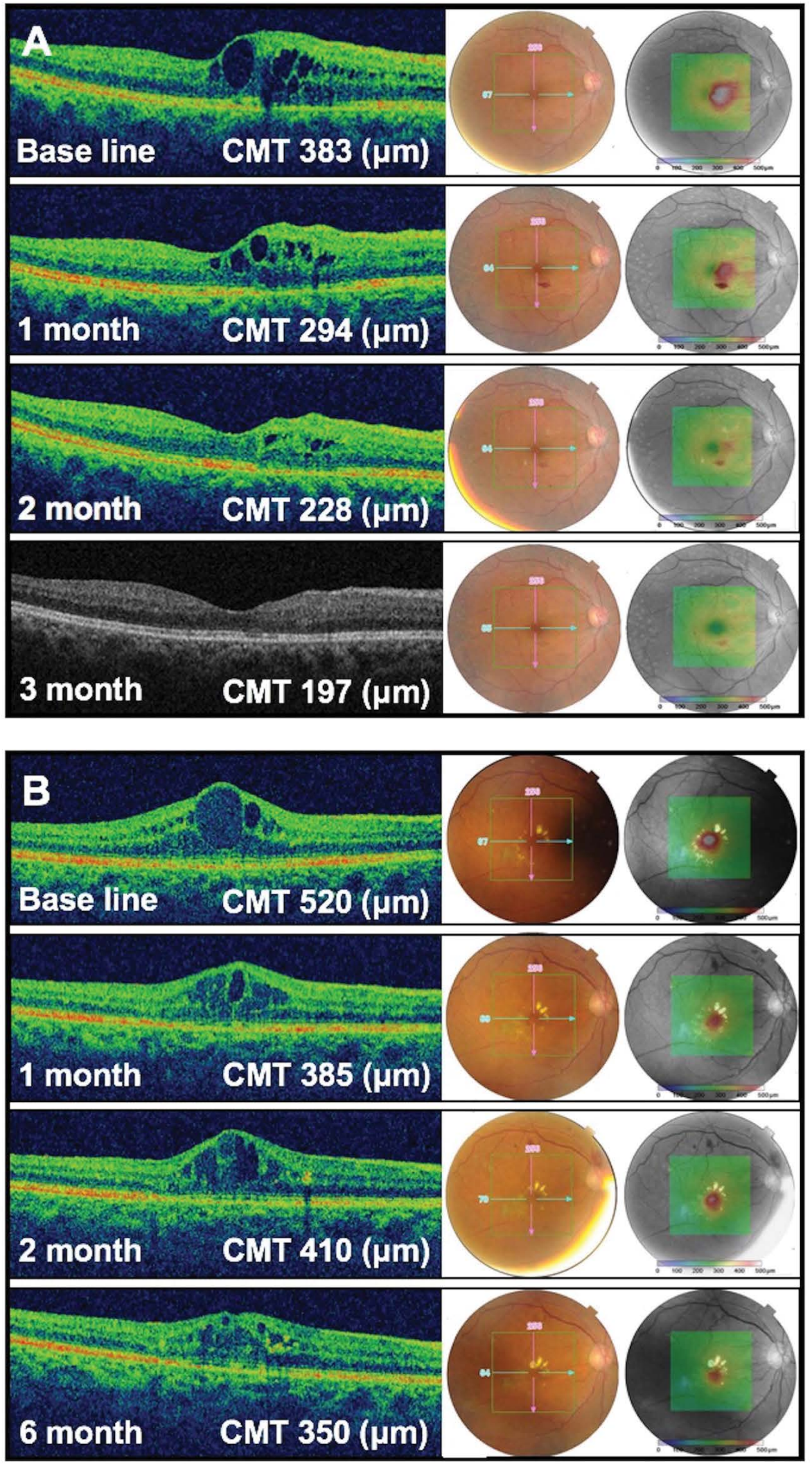

Figure 2: Optical coherence tomography findings and colour fundus photography after subthreshold laser therapy using a pattern scan laser photocoagulator.

A) A patient with central retinal vein occlusion. Macular edema was decreased at 1 month after treatment and improved to $197 \mu \mathrm{m}$ of the normal foveal thickness at 3 months. Although intraretinal haemorrhage is observed below the fovea, it was soon absorbed without requiring treatment; B) A patient with moderate non-proliferative diabetic retinopathy followed for up to 6 months after PT-STLT. Although the responsible macular edema lesion was directly adjacent to the fovea and considered difficult to manage with a conventional laser method, this case was managed effectively using PS-STLT. The treatment of coagulation spots on the temporal side of the macula was performed prior to closure of the microaneurysms.

decrease of $20 \%$ or more at 3 months postoperatively; Figure 2 shows representative examples.
The baseline CMT values and CMT changes 3 months postoperatively classified into three categories (Table 1 ). 
Table 1: Baseline central macular thickness (CMT) and changes 3 months postoperatively classified into three categories according to optical coherence tomography findings $(n=24)$.

\begin{tabular}{|c|c|c|c|}
\hline Base line/ $/$ Change in CMT & Improved & Unchanged & Worsened \\
\hline $\mathrm{CMT} \leq 300 \mu \mathrm{m}(\mathrm{n}=6)$ & 1 & 4 & 1 \\
\hline $300 \mu \mathrm{m}<\mathrm{CMT} \leq 400 \mu \mathrm{m}(\mathrm{n}=10)$ & 5 & 2 & 3 \\
\hline $400 \mu \mathrm{m}<\mathrm{CMT} \leq 600 \mu \mathrm{m}(\mathrm{n}=5)$ & 3 & 2 & 0 \\
\hline CMT > $600 \mu \mathrm{m}(\mathrm{n}=3)$ & 1 & 1 & 1 \\
\hline
\end{tabular}

${ }^{*}$ A change in CMT was defined as a change of $20 \%$ or more. Improved $=$ a $20 \%$ or greater decrease in CMT, unchanged $=$ a CMT change from $0 \%-20 \%$, worsened $=$ a CMT decrease of $20 \%$ or greater. CMT: Central Macular Thickness.

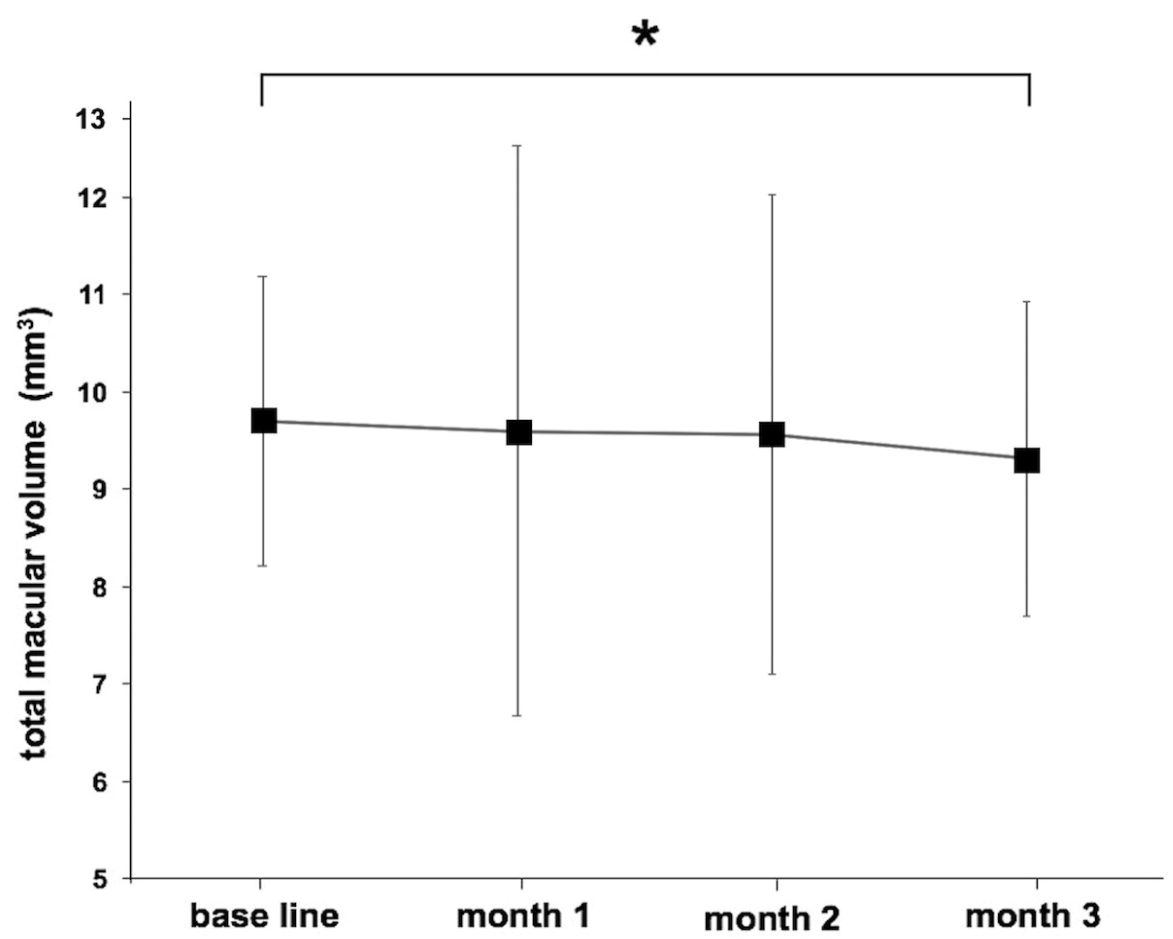

Figure 3: Changes in total macular volume over time after subthreshold laser therapy using a pattern scan laser photocoagulator.

Although the total macular volume shows no statistically significant change at 1 month or 2 months after treatment, a significant decrease is observed at 3 months $(P<0.01$, one-way repeated measures ANOVA).

As a result, among the cases in which the baseline CMT was between $300 \mu \mathrm{m}$ and $400 \mu \mathrm{m}$, three eyes showed a CMT increase of $20 \%$ or more. However, in the zone (according to ETDRS grid) where the laser irradiation was mainly performed for the most severe region of $\mathrm{ME}$, one of these patients showed a reduction in highest zone from 453 to $387 \mu \mathrm{m}$, which was an improvement of $14.6 \%$. The other patient's highest zone changed from 463 to $456 \mu \mathrm{m}$, and from 559 to $607 \mu \mathrm{m}$. In other words, these two cases were unchanged (not worse) 3 months after baseline.

In one eye with a baseline CMT > $600 \mu \mathrm{m}$ and a CMT of $20 \%$ or more, the area with the most severe ME showed a similar reduction from 756 to $522 \mu \mathrm{m}$ (31.0\%).

The baseline TMV was 9.7 \pm 1.6 (range from 7.65-13.71) $\mathrm{mm}^{3}$ and the values at 1,2 , and 3 months postoperatively were $9.6 \pm 3.1 \mathrm{~mm}^{3}, 9.6 \pm 2.6 \mathrm{~mm}^{3}$, and $9.3 \pm 1.7 \mathrm{~mm}^{3}$, respectively. The change in TMV was not significant at 1 month $(P=1.0$, one-way repeated measures ANOVA) but tended to be reduced at 2 months $(P=1.0)$; a significant reduction was observed 3 months after the operation $(P<$ 0.01; Figure 3).

\section{Alterations in visual acuity at 1, 2, and 3 months}

Figure 4 shows scatter diagram of changes in best-corrected visual acuity (logMAR) between base line and 3 months postoperatively. The baseline logMAR value was $0.26 \pm 0.32$; the values at 1,2 , and 3 months postoperatively were $0.28 \pm 0.29,0.25 \pm 0.32$ and 0.25 \pm 0.31 , respectively. There was no significant change in BCVA (logMAR) over time after PS-STLT $(P=1.0,1.0$, and 1.0 , respectively; one-way repeated measures ANOVA).

\section{Treatment outcomes for central retinal vein occlu- sion and branch retinal vein occlusion}

Among the 24 enrolled subjects, five patients with BRVO and two patients with CRVO were included among the 17 eyes with DR. The mean CMT reductions in the patients with BRVO were $15.9 \%$ ( $351.6 \pm 204.2$ to 295.6 $\pm 124.8 \mu \mathrm{m})$; the patient with CRVO showed a CMT reduction of $31.5 \%(403 \pm 28.3$ to $276 \pm 111.7 \mu \mathrm{m})$. BCVA ( $\log M A R)$ was not improved or worsened by 0.2 or more and visual acuity was maintained. 


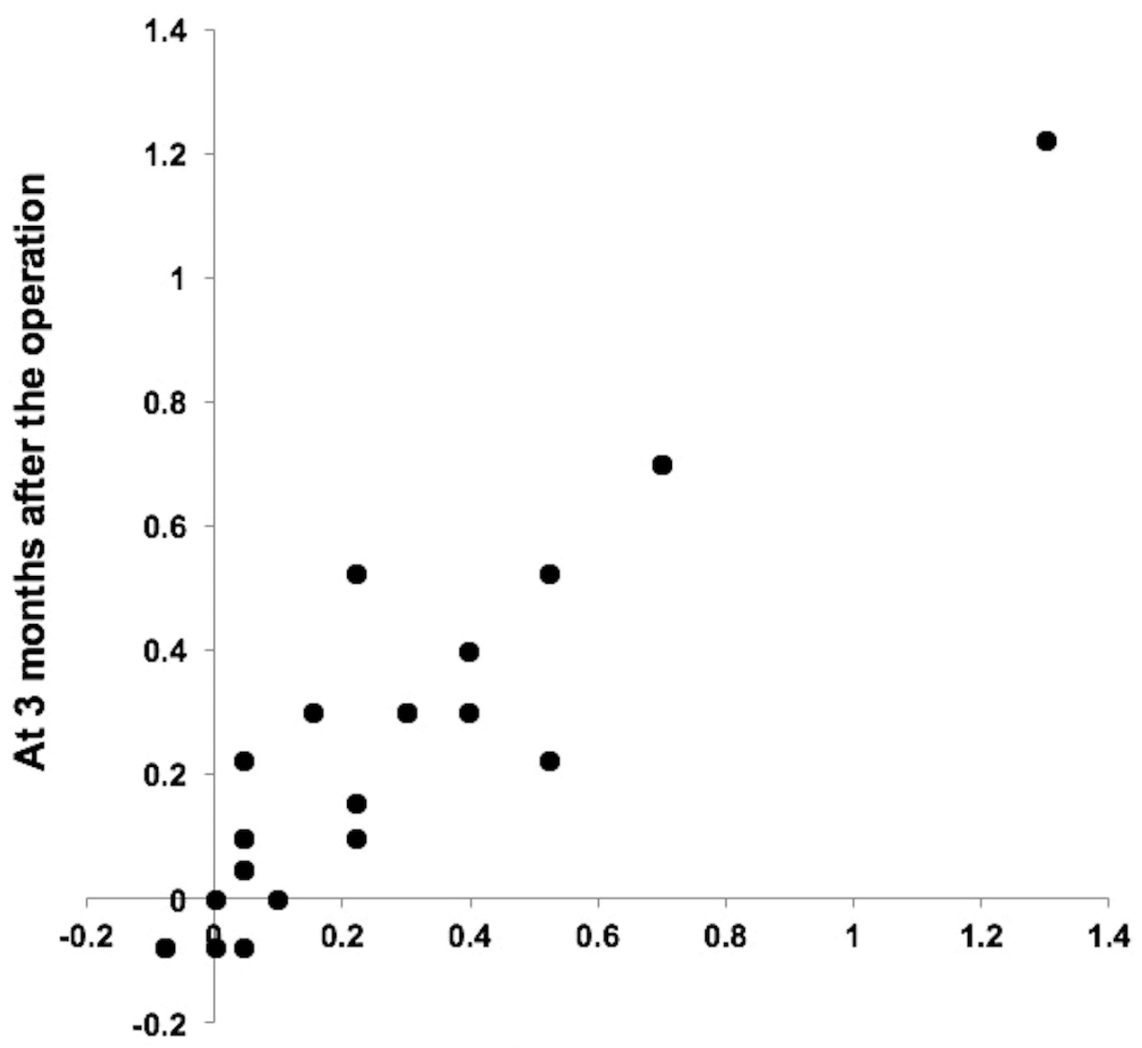

base line

Figure 4: Changes in best-corrected visual acuity (logMAR) after subthreshold laser therapy using a pattern scan laser photocoagulator $(n=24)$.

Changes in best-corrected visual acuity after subthreshold laser therapy using a pattern scan laser photocoagulator between base line and 3 months after the operation.

\section{Discussion}

Using OCT findings, this study investigated the PSSTLT treatment outcomes of 24 patients (24 eyes) after 3 months of postoperative follow-up. Ten eyes (41.7\%) showed a decrease in CMT of $20 \%$ or more; conversely, in cases in which CMT increased, it mainly decreased in the ETDRS grid where PS-STLT was performed. A significant reduction in TMV was noted at 3 months $(P<0.01)$. In addition, PS-STLT was confirmed to be effective not only for DME but also for ME in BRVO and CRVO.

In a previous study in which Japanese patients with DME were treated with subthreshold laser photocoagulation using a micropulse laser, Ohkoshi and Yamaguchi reported that the mean CMT was $300.7 \mu \mathrm{m}$ at 3 months postoperatively versus $341.8 \mu \mathrm{m}$ preoperatively [17]; namely, a reduction of $12.0 \%$ was obtained. Takatsuna, et al. reported that the mean CMT was $409.8 \mu \mathrm{m}$ at 3 months postoperatively versus $504.3 \mu \mathrm{m}$ preoperatively [18]; that is, a reduction of $18.7 \%$ was obtained. According to these reports, the effectiveness of micropulse lasers was better than that of PS-STLT because our results showed a reduction of $7.9 \%$. However, the report by Ohkoshi and Yamaguchi excluded severe cases with a CMT exceeding $600 \mu \mathrm{m}$ (our study included three cases), and the possibility cannot be denied that this criterion may have affected the differences in treatment outcomes. In addition, from the results of the present study in which there was no significant reduction in CMT, six cases $(25.0 \%)$ with a CMT less than $300 \mu \mathrm{m}$ were included to treat para-foveal ME, which may be reflected in the results. Although this study included a relatively small number of cases, among the cases in which CMT decreased by $20 \%$ or more 3 months postoperatively, PS-STLT showed a $41.7 \%$ reduction compared with the previously reported value of $39.5 \%$; that is, similar results were obtained.

Regarding the duration in which the ME reduction effect was obtained, TMV showed a significant reduction 3 months postoperatively in the present study. Even in the study by Luttrull and Spink using a micropulse diode laser, a reduction in ME was reported at 3 months after the operation, but no significant change was observed at 1 or 2 months postoperatively [12]; that is, micropulse laser treatment required the same duration as that shown in our research before a therapeutic effect was obtained. However, in a previous report by Ohkoshi and Yamaguchi, CMT was decreased 1 month postoperatively and TMV was reduced 2 months postoperatively [17], suggesting the possibility that the micropulse laser showed effects earlier than PS-STLT. Regarding this consideration, the restoration response of the RPE to thermal injury from subthreshold laser photocoagulation activates a cellular cascade through the RPE, which is typically damaged considerably by the conventional 
method, resulting in the therapeutic effects of laser treatment for fluid absorption from an edematous retina [19]. From the point of view of RPE stimulation, it is assumed that there is a difference in irradiation time between the microsecond duration of the micropulse laser and millisecond duration of the pattern scan laser. In addition, because thermal tissue damage is proportional to the exposure time [20], irradiation time is also important when considering tissue damage. Micropulse laser oscillation is a repetitive oscillation in which the laser is switched on and off in an extremely short duration. In the off state, the rise in tissue temperature and thermal diffusion to surrounding tissues are associated with the release of inflammatory cytokines, which can cause ME aggravation to be suppressed. Thus, the micropulse laser's duration seemed to be the reason for obtaining an effect earlier than with the PS-STLT's irradiation duration of $20 \mathrm{~ms}$.

Postoperative visual acuity was unchanged, as in previous reports $[12,17,18]$; therefore, the disease duration and other factors should be considered. In addition, since persons of non-white races have more pigment than those of white races, the additional pigment absorbs more laser energy, and theoretically, tends to cause retinal damage. Further study based on racial differences is necessary.

Although anti-VEGF therapy is currently the first choice for DME treatment, various problems remain. Repeated administration is necessary because of the short acting effects and DME tends to recur. Moreover, this treatment is also associated with a risk for ocular infection, a very high cost to the healthcare system, and the burdens of frequent intravitreal injections on patients and physicians. Accordingly, efforts to reduce the number of administrations efficiently are emphasized. From this point as well, retinal photocoagulation is expected to establish a combination treatment strategy centered on anti-VEGF therapy.

In recent years, retinal photocoagulation methods have definitely advanced. Initially, severe complications were shown with the conventional photocoagulation method in which coagulation spots expanded because of atrophic creep [3]; especially, the scarring spread further at the retinal posterior pole [21]. With regard to retinal damage, conventional laser applications would cause full-thickness retinal damage to not only the photoreceptors but also to the inner retina and nerve fibre layer [3] and can even rupture the internal limiting membrane and coagulate the vitreous [19]. However, PASCAL $^{\circledR}$ (Topcon, Tokyo, Japan) has been developed, which is capable of photocoagulation in a short duration of 10-30 ms and limits the irradiation target to the RPE despite its high power [22]. The authors found that a high-power short-duration method causes little expansion of the coagulation spots, which may become a postoperative adverse event [23].
More recently, the concept of subthreshold laser photocoagulation has become more widespread as a treatment for diffuse DME. Regarding the response mechanism to subthreshold laser photocoagulation has become, according to a study in which a micropulse laser was used to irradiate an RPE cell culture, sublethal photothermal stimulation with a micropulse laser may have facilitated heat shock protein (Hsp)70 expression in the RPE without inducing cellular damage [24]. Several studies have been published showing that $\mathrm{Hsp} 70$ can protect against numerous stresses including heat shock [25], oxidative stress [26], apoptotic stimuli $[27,28]$, and ischemia $[29,30]$. That is, upregulation of Hsp70 expression induced by laser stimuli is thought to play an important role in the improvement of ME.

Moreover, as described above, since subthreshold laser photocoagulation does not cause retinal photoreceptor damage and cell death, which have created serious problems in the past, there is no postoperative scotoma and it does not cause complications. Therefore, even in cases that could not obtain effective treatment from the initial irradiation, repeating the treatment is possible at the same location as required since this method is extremely minimally invasive and could be applied close to the parafoveal area where there is a risk of creating severe scotoma; this forms the basis for irradiation being possible. In the PS-STLT performed in this study, since the laser power threshold was lowered by $10 \mathrm{~mW}$ in each adjustment down from $100 \mathrm{~mW}$ to obtain an invisible spot, RPE atrophy may occur in this titration area in the long term. However, the short duration method has great advantages compared with the conventional method in terms of tissue restoration [31]. There is the possibility of photoreceptor migration into the coagulated area, resulting in a restoration of visual sensitivity at the lesion site [32], and coagulation spots can even disappear [19]. These findings have also supported the safety of this method. Furthermore, as shown in this study, performing PT-STLT earlier for cases in which the ME is close to the fovea and where microaneurysms were not responsible for ME is thought to be effective in preventing prolongation, even when CMT itself is reduced.

This study demonstrated the possibility of performing subthreshold laser coagulation using a general pattern scan laser, although it was somewhat less effective than micropulse laser photocoagulation. PS-STLT can be expected to be one of the treatments for ME accompanied by retinal vascular disease.

\section{Acknowledgement}

The authors are grateful to Atsuko Tsutsumi at Tsutusmi Eye Clinic (Tokyo, Japan) for designing the laser application system.

\section{References}

1. Klein R, Klein BE, Moss SE, Davis MD, DeMets DL (1984) 
The Wisconsin epidemiologic study of diabetic retinopathy. IV. Diabetic macular edema. Ophthalmology 91: 14641474.

2. Early Treatment Diabetic Retinopathy Study research group (1985) Photocoagulation for diabetic macular edema. Early Treatment Diabetic Retinopathy Study report number 1. Arch Ophthalmol 103: 1796-1806.

3. Schatz H, Madeira D, McDonald HR, Johnson RN (1991) Progressive enlargement of laser scars following grid laser photocoagulation for diffuse diabetic macular edema. Arch Ophthalmol 109: 1549-1551.

4. Guyer DR, D'Amico DJ, Smith CW (1992) Subretinal fibrosis after laser photocoagulation for diabetic macular edema. Am J Ophthalmol 113: 652-656.

5. Varley MP, Frank E, Purnell EW (1988) Subretinal neovascularization after focal argon laser for diabetic macular edema. Ophthalmology 95: 567-573.

6. Writing Committee for the Diabetic Retinopathy Clinical Research Network, Fong DS, Strauber SF, Aiello LP, Beck RW, et al. (2007) Comparison of the modified Early Treatment Diabetic Retinopathy Study and mild macular grid laser photocoagulation strategies for diabetic macular edema. Arch Ophthalmol 125: 469-480.

7. Roider J, Michaud NA, Flotte TJ, Birngruber R (1992) Response of the retinal pigment epithelium to selective photocoagulation. Arch Ophthalmol 110: 1786-1792.

8. Roider J (1999) Laser treatment of retinal diseases by subthreshold laser effects. Semin Ophthalmol 14: 19-26.

9. Friberg TR, Karatza EC (1997) The treatment of macular disease using a micropulsed and continuous wave $810-\mathrm{nm}$ diode laser. Ophthalmology 104: 2030-2038.

10. Moorman CM, Hamilton AM (1999) Clinical applications of the MicroPulse diode laser. Eye (Lond) 13: 145-150.

11. Laursen ML, Moeller F, Sander B, Sjoelie AK (2004) Subthreshold micropulse diode laser treatment in diabetic macular oedema. Br J Ophthalmol 88: 1173-1179.

12. Luttrull JK, Musch MC, Mainster MA (2005) Subthreshold diode micropulse photocoagulation for the treatment of clinically significant diabetic macular edema. $\mathrm{Br} \mathrm{J}$ Ophthalmol 89: 74-80.

13. Sivaprasad S, Sandhu R, Tandon A, Sayed-Ahmed K, McHugh DA (2007) Subthreshold micropulse diode laser photocoagulation for clinically significant diabetic macular oedema: a three-year follow up. Clin Exp Ophthalmol 35: 640-644.

14. Lavinsky D, Cardillo JA, Melo LA Jr., Dare A, Farah ME, et al. (2011) Randomized clinical trial evaluating mETDRS versus normal or high-density micropulse photocoagulation for diabetic macular edema. Invest Ophthalmol Vis Sci 52: 4314-4323.

15. Shiraya T, Kato S, Araki F, Ueta T, Abe H, et al. (2017) Experimental verification of subthreshold laser therapy using conventional pattern scan laser. PLoS One 12: e0184392.

16. Kanda $Y$ (2013) Investigation of the freely available easyto-use software 'EZR' for medical statistics. Bone Marrow Transplant 48: 452-458.

17. Ohkoshi K, Yamaguchi T (2010) Subthreshold micropulse diode laser photocoagulation for diabetic macular edema in Japanese patients. Am J Ophthalmol 149: 133-139.

18. Takatsuna $Y$, Yamamoto $S$, Nakamura $Y$, Tatsumi T, Arai $M$, et al. (2011) Long-term therapeutic efficacy of the sub- threshold micropulse diode laser photocoagulation for diabetic macular edema. Jpn J Ophthalmol 55: 365-369.

19. Lavinsky D, Sramek C, Wang J, Huie P, Dalal R, et al. (2014) Subvisible retinal laser therapy: titration algorithm and tissue response. Retina 34: 87-97.

20. Mainster MA (1999) Decreasing retinal photocoagulation damage: principles and techniques. Semin Ophthalmol 14: 200-209.

21. Maeshima K, Utsugi-Sutoh N, Otani T, Kishi S (2004) Progressive enlargement of scattered photocoagulation scars in diabetic retinopathy. Retina 24: 507-511.

22. Blumenkranz MS, Yellachich D, Andersen DE, Wiltberger MW, Mordaunt D, et al. (2006) Semiautomated patterned scanning laser for retinal photocoagulation. Retina 26: 370376.

23. Shiraya $T$, Kato $S$, Shigeeda $T$, Yamaguchi $T$, Kaiya $T$ (2014) Comparison of burn size after retinal photocoagulation by conventional and high-power short-duration methods. Acta Ophthalmol 92: e585-e586.

24. Inagaki K, Shuo T, Katakura K, Ebihara N, Murakami A, et al. (2015) Sublethal Photothermal Stimulation with a Micropulse Laser Induces Heat Shock Protein Expression in ARPE-19 Cells. J Ophthalmol 2015: 729792.

25. Mosser DD, Caron AW, Bourget L, Denis-Larose C, Massie B (1997) Role of the human heat shock protein hsp70 in protection against stress-induced apoptosis. Mol Cell Biol 17: 5317-5327.

26. Bellmann K, Jaattela M, Wissing D, Burkart V, Kolb $H$ (1996) Heat shock protein hsp70 overexpression confers resistance against nitric oxide. FEBS Lett 391: 185-188.

27. Jäättelä M, Wissing D, Kokholm K, Kallunki T, Egeblad M (1998) Hsp70 exerts its anti-apoptotic function downstream of caspase-3-like proteases. EMBO J 17: 6124-6134.

28. Buzzard KA, Giaccia AJ, Killender M, Anderson RL (1998) Heat shock protein 72 modulates pathways of stress-induced apoptosis. J Biol Chem 273: 17147-17153.

29. Mestril R, Chi SH, Sayen MR, O'Reilly K, Dillmann WH (1994) Expression of inducible stress protein 70 in rat heart myogenic cells confers protection against simulated ischemia-induced injury. J Clin Invest 93: 759-767.

30. Williams RS, Thomas JA, Fina M, German Z, Benjamin IJ (1993) Human heat shock protein 70 (hsp70) protects murine cells from injury during metabolic stress. J Clin Invest 92: 503-508.

31. Paulus YM, Jain A, Gariano RF, Stanzel BV, Marmor M, et al. (2008) Healing of retinal photocoagulation lesions. Invest Ophthalmol Vis Sci 49: 5540-5545.

32. Sher A, Jones BW, Huie P, Paulus YM, Lavinsky D, et al. (2013) Restoration of retinal structure and function after selective photocoagulation. J Neurosci 33: 6800-6808. 